\title{
PELATIHAN DIGITAL ENTREPRENEURSHIP UNTUK MEWUJUDKAN KEMANDIRIAN EKONOMI PADA MASA PANDEMI DI DESA SALAMKANCI
}

\author{
Fadhilah Rahmawati $^{\star 1}$, Agnira Rekha ${ }^{2}$, Megita Dwi Pamungkas ${ }^{3}$ \\ $1,2,3$ UniversitasTidar \\ *e-mail: fadhilahrahmawati@untidar.ac.id1', agnirarekha@untidar.ac.id², megitadwip@untidar.ac.id²
}

\begin{abstract}
The purpose of this activity is to overcome the problems faced by partners, namely the lack of public awareness to utilize technology to entrepreneurship to meet economic needs during the pandemic. The emergence of the current problem is due to a lack of public knowledge related to the use of technology in entrepreneurship. People think that entrepreneurship requires a lot of capital and technology can only help businesses that have grown. With this activity, it is expected that the public has the awareness to utilize technology to start and support entrepreneurship activities for various commodities so that economic independence can be achieved and improve the welfare of the community, especially during the pandemic.

The approach used in this activity is PRA (Participatory Rural Appraisal). This approach engages people to understand problems and increases the participation of the community to solve their problems. In this activity, residents represented by PKK mothers were given socialization about the use of technology for entrepreneurship in Salamkanci Village, Bandongan Subdistrict, Magelang Regency continued counseling on economic independence, then given motivation and training on the use of technology in entrepreneurship to practice training results.
\end{abstract}

Keywords: digital, entrepreneurship, economic independence

\begin{abstract}
Abstrak
Tujuan dari kegiatan ini adalah mengatasi permasalahan yang dihadapi oleh mitra yaitu kurangnya kesadaran masyarakat untuk memanfaatkan teknologi untuk berwirausaha guna memenuhi kebutuhan ekonomi pada masa pandemic. Munculnya permasalahan saat ini karena kurangnya pengetahuan masyarakat terkait penggunaan teknomogi dalam berwirausaha. Masyarakat berpikir bahwa berwirausaha membutuhkan banyak modal dan teknologi hanya dapat membantu usaha yang sudah berkembang. Dengan adanya kegiatan ini diharapkan masyarakat memiliki kesadaran untuk memanfaatkan teknologi untuk memulai dan menunjang kegiatan berwirausaha untuk berbagai komoditas sehingga kemandirian ekonomi dapat dicapai dan meningkatkan kesejahteraan masyarakat, terutama pada masa pandemic.

Pendekatan yang digunakan dalam kegiatan ini adalah PRA (Parcitipatory Rural Appraisal). Pendekatan ini melibatkan masyarakat untuk memahami masalah dan meningkatkan partisipasi masyarakt untuk menyelesaikan masalah mereka sendiri. Dalam kegiatan ini warga yang diwakili oleh ibu-ibu anggota PKK diberikan sosialisasi tentang penggunaan teknologi untuk berwirausaha di Desa Salamkanci, Kecamatan Bandongan, Kabupaten Magelang dilanjutkan penyuluhan tentang kemandirian ekonomi, kemudian diberi motivasi dan pelatihan tentang pemanfaatan teknologi dalam berwirausaha untuk mempraktekkan hasil pelatihan.
\end{abstract}

Kata kunci: digital, entrepreneurship, kemandirian ekonomi 


\section{PENDAHULUAN}

Desa Salamkanci merupakan salah satu desa di Kecamatan Bandongan yang berjarak $9 \mathrm{~km}$ dari Universitas Tidar dan berjarak $6 \mathrm{~km}$ dari alun-alun Kota Magelang. Akses menuju kota dari desa Salamkanci melewati jalan yang sedikit terjal dan berliku. Sebagian besar kegiatan sehari-hari masyarakat desa Salamkanci berdagang di rumah. Beberapa di antaranya merupakan ibu rumah tangga yang berjualan makanan dari rumah dengan memajang dagangan mereka di depan rumah. Selain itu, terdapat juga beberapa toko kelontong dipinggir jalan yang menjajakan kebutuhan rumah tangga. padahal, sebenarnya warga desa dapat memanfaatkan teknologi yang ada untuk memaksimalkan usaha yang mereka kembangkan.

Keterbatasan penggunaan teknologi juga menjadi alas an masyarakat untuk tidak berwirausaha dan tidak mengembangkan usahanya. Hal serupa yang kami lihat Ketika survei awal ke lokasi mitra kegiatan, yaitu desa Salamkanci.

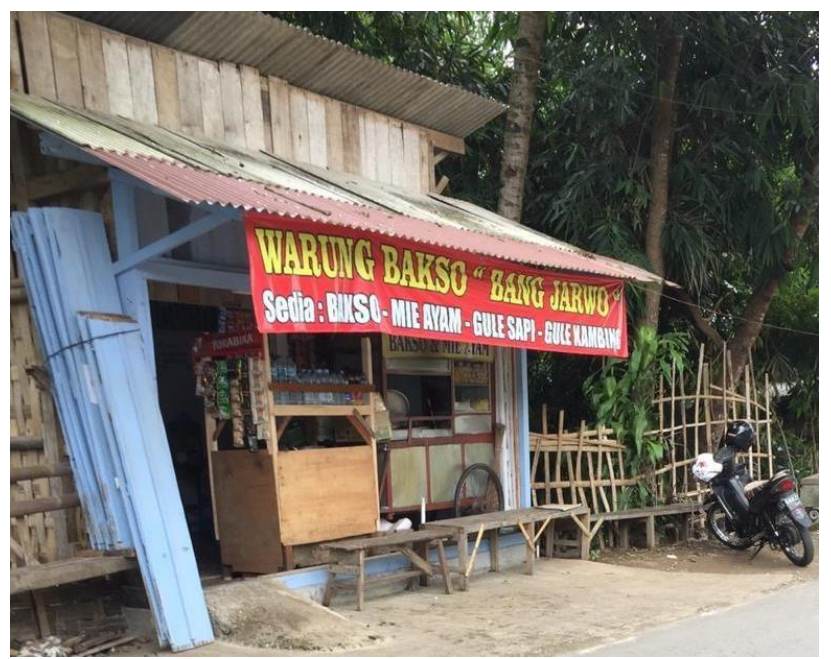

\section{Gambar 1. Kondisi Usaha Rumahan Warga Desa Salamkanci}

Permasalahan minimnya ketrampilan masyarakat dan sempitnya lapangan pekerjaan serta kurangnya perhatian dari pemerintah untuk menciptakan lapangan pekerjaan (Misnawati \& Yusriadi, 2018). Pengangguran dan kemiskinan masih menjadi momok bangsa Indonesia bahkan menjadi PR besar pemerintah Indonesia, karena kondisi tersebut lambat laun akan mengganggu stabilitas ekonomi Indonesia, apalagi pada masa pandemic. Oleh karena itu, peningkatan pengetahuan kewirausahaan menjadi suatu keniscayaan, dengan mengembangkan jiwa kewirausahaan di skala paling kecil, yaitu keluarga. Sehingga dapat terbentuklah jiwa kewirausahaan pada diri ibu rumah tangga. hal tersebut menjadi solusi bagi 
permasalahan di atas kaema akan sulit negeri Indonesia ini menjadi negara yang kuat dan memiliki stabilitas ekonomi tanpa didorong oleh bertambhanya start up baru yang memulai usaha yang pada akhirnya akan memunculkan lowongan pekerjaan baru bagi bangsa Indonesia.

Masyarakat sekarang sangat lekat dengan teknologi informasi dimana mereka terbiasa dengan internet dan gadget, namun banyak masyarakat yang tidak memanfaatkan alat teknologi tersebut untuk hal-hal positif terkhusus usaha atau bisnis yang menghasilkan. Sebagaimana diungkapkan oleh Hardiyanto (2018) bahwa fenomena digital entrepreneurship memiliki peluang yang lebar dimasa yang akan dating dan itu harus menjadi perhatian kita semua. Sudah bukan hal mustahil terlahir pengusaha sukses dari tanah air kita. Contoh pengusaha sukses berkat pemanfaatan teknologi informasi seperti grab, gojek, bukalapak, Tokopedia, olx, dan lain sebagainya. Namun banyak juuga masyarakat yang tidak memanfaatkan sehingga menghasilkan pendapatan.

Potensi teknologi informasi sangat terbuka lebar, saat ini orang akan lebih mudah menjual disbanding masa lalu, tanpa perlu memilii toko atau lahan usaha sudah bisa memasarkan di marketplace atau media social, mempromosikan barang atau jasa tidak lagi sulit dan dapat dijangkau oleh semua orang sampai mancanegara. Digital entrepreneurship bisa digalakkan dengan Pendidikan dan pelatihan bagi ibu rumah tangga. dengan digital entrepreneurship diharapkan dapat mengurangi permasalahan pemerintah terkait dengan pengangguran dan kemiskinan, terutama pada masa pandemi ini.

Pelatihan digital entrepreneurship mendorong masyarakat agar membuka usaha dengan memanfaatkan teknologi informasi. Bentuk usahanya pun bisa beraneka ragam, bisa bersifat barang ataupun jasa. Apabila sudah memiliki produk maka kita dorong untuk menjualnya secara online dengan memanfaatkan social media atau market place yang sudah terkenal seperti shopee, bukalapak, Tokopedia, dan lain sebagainya. Apabila belum ada produk atau jasa, maka didorong agar ide kreatif mereka munculm sehingga masyarakat memiliki keyakinan untuk melangkah menjadi pengsusaha.

Permasalahan yang lebih mendasar adalah kurangnya pengetahuan tentang bagaimana memanfaatkan teknologi untuk memulai usaha. Selain itu terdapat permasalahan terkait dengan pemanfaatan teknologi untuk mengembangkan usaha. Pengetahuan masyarakat terkait penggunaan market place atau social media untuk berwirausaha masih rendah. Dengan pengetahuan untuk memanfaatkan teknologi masyarakat dapat menjual barang atau jasa yang mereka produksi sehingga mengurangi dampak pengganggguran maupun pemutusan hubungan kerja (PHK) pada masa pandemi.2. METODE 
Metode kegiatan ini berupa sosialisasi, penyuluhan dan pelatihan kepada ibu-ibu anggota PKK Desa Salamkanci, Kecamatan Bandongan, Kabupaten Magelang. Setelah diberikan pelatihan, selanjutnya peserta diberi bantuan kuota internet untuk digunakan di gadget masing-masing dengan pendampingan tim pelaksana. Sasaran dalam kegiatan ini adalah Ibu-ibu anggota PKK Desa Salamkanci, Kecamatan Bandongan, Kabupaten Magelang.

Kegiatan pengabdian ini dilakukan dalam 3 tahap yaitu tahap persiapan, tahap pelaksanaan pelatihan dan tahap evaluasi. Pada tahap persiapan kegatan yang dilakukan adalah survey, pengamatan dan penentuan lokasi dan sasaran serta penyususnan bahan/materi sosialisasi, penyuluhan dan pelatihan. Kemudian pada tahap pelaksanaan pelatihan kegiatan yang dilakukan adalah sosialisasi tentang kewirausahaan dengan pemanfaatan teknologi, penyuluhan tentang kemandirian ekonomi, motivasi dan pelatihan kesuksesan berwirausaha dengan pemanfaatan tekonologi serta pemberian kuota internet kepada peserta. Pada tahap akhir atau evaluasi adalah pengamatan hasil pemanfaatan teknologi untuk berwirausaha warga.

\section{HASIL DAN PEMBAHASAN}

Pelatihan digital entrepreneurship untuk mewujudkan kemandirian ekonomi pada masa pandemi merupakan salah satu Program Kemitraan Masyarakat yang dijalankan oleh Ibu Fadhilah Rahmawati, M.Pd., Ibu Agnira Rekha, M.Pd., dan Bapak Megita Dwi Pamungkas, M.Pd yang merupakan Dosen Fakultas Keguruan dan IImu Pendidikan di Universitas Tidar. Pelatihan ini dilaksanakan selama 3 minggu yaitu pada hari Minggu, 22 Agustus 2021 sampai hari Minggu, 5 September 2021 yang dilaksanakan di salah satu rumah warga Desa Salamkanci, Kec. Bandongan, Kab. Magelang. Adapun agenda dalam 3 hari tersebut adalah sebagai berikut.

Pada hari pertama, Minggu, 22 Agustus 2021, pelatihan digital entrepreneurship untuk mewujudkan kemandirian ekonomi pada masa pandemi dilaksanakan di salah satu rumah warga Desa Salamkanci, Kec. Bandongan, Kab. Magelang yang dihadiri oleh ibu-ibu anggota PKK Desa Salamkanci. ibu-ibu anggota PKK sangat antusias ketika pelaksanaan pelatihan berlangsung. Pada hari pertama, Ibu Fadhilah Rahmawati, M.Pd. selaku pemateri membuka pelatihan dan memberikan informasi kepada ibu-ibu anggota PKK bahwa program ini merupakan salah satu program kemitraan masyarakat untuk menjalankan salah satu Tridharma Perguruan Tinggi yaitu pengabdian kepada masyarakat yang salah satunya adalah memberikan pelatihan digital entrepreneurship untuk mewujudkan kemandirian ekonomi pada 
masa pandemi di Desa Salamkanci dengan harapan dapat meningkatkan kesadaran masyarakat dalam memanfaatkan teknologi untuk berwirausaha guna memenuhi kebutuhan ekonomi pada masa pandemi. Setelah membuka pelatihan ini, Ibu Fadhilah Rahmawati, M.Pd. mempersilahkan ibu-ibu anggota PKK untuk memperhatikan materi mengenai pengenalan digital entrepreneurship yang telah disiapkan oleh tim sebelumnya.

Pada hari ini masih banyak ibu-ibu anggota PKK yang bercerita mengenai kesulitan penggunaan teknologi dalam berwirausaha. Kurangnya wawasan ibu-lbu PKK dalam teknologi untuk kewirausahaan membuat mereka menggunakan sistem tradisional dalam berwirausaha. Pemateri juga menjelaskan mengenai pentingnya pemanfaatan teknologi dalam berwirausaha di masa pandemi. Saat penjelasan ibu-ibu anggota PKK antusias dengan menanyakan beberapa pertanyaan mengenai digital entrepreneurship.

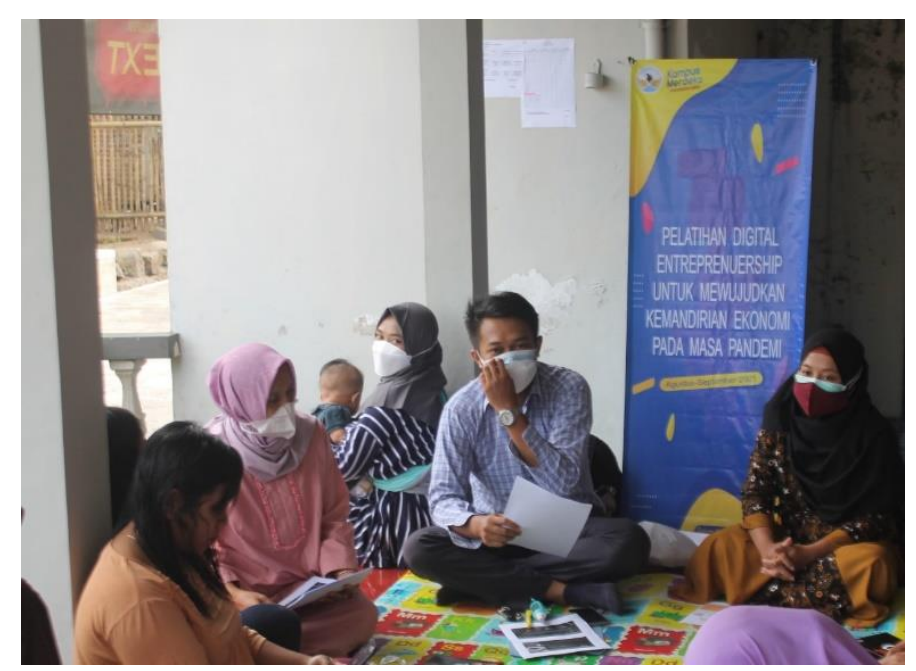

\section{Gambar 2. Pelaksanaan Pelatihan Hari Pertama}

Pada hari kedua, Minggu, 29 Agustus 2021 ibu-ibu anggota PKK Desa Salamkanci diberikan pelatihan penggunaan e-commerce. E-commerce merupakan pembelian dan penjualan secara elektronik, jadi lbu-ibu diberikan modul pelatihan e-commerce yang sudah disediakan oleh tim. Platform yang digunakan di modul ini adalah shopee. Ibu-ibu anggota PKK sangat antusias dalam proses diskusi tentang penggunaan e-commerce ini dikarenakan pada pertemuan sebelumnya ibu-ibu anggota PKK sudah memahami tentang digital entrepreneurship. Setelah ibu-ibu anggota PKK memahami materi penggunaan e-commerce, kemudian dilanjutkan dengan simulasi penggunaan e-commerce di smartphone ibu-ibu anggota PKK. 


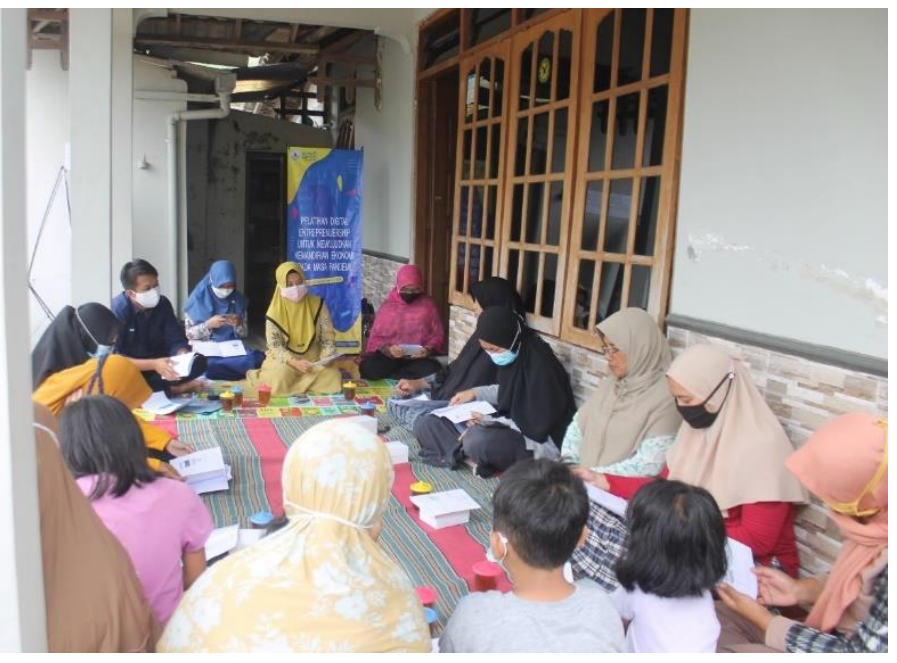

Gambar 3. Pelaksanaan Hari Kedua

Pada hari ketiga, Minggu, 5 September 2021 pelatihan digital entrepreneurship di Desa Salamkanci, Kec. Bandongan, Kab. Magelang adalah penggunaan jasa transportasi online. Ibu Fadhilah Rahmawati, M.Pd. memaparkan mengenai penggunaan jasa transportasi online untuk mendukung digital entrepreneurship. Pemateri memberikan beberapa kelebihan dan kemudahan ketika menggunakan jasa transportasi online daripada harus membeli secara langsung. Platform yang digunakan dalam pelatihan penggunaan jasa transportasi online disini adalah grab. Ibu-ibu anggota PKK kemudian mensimulasikan penggunaan jasa transportasi online melalui aplikasi grab.

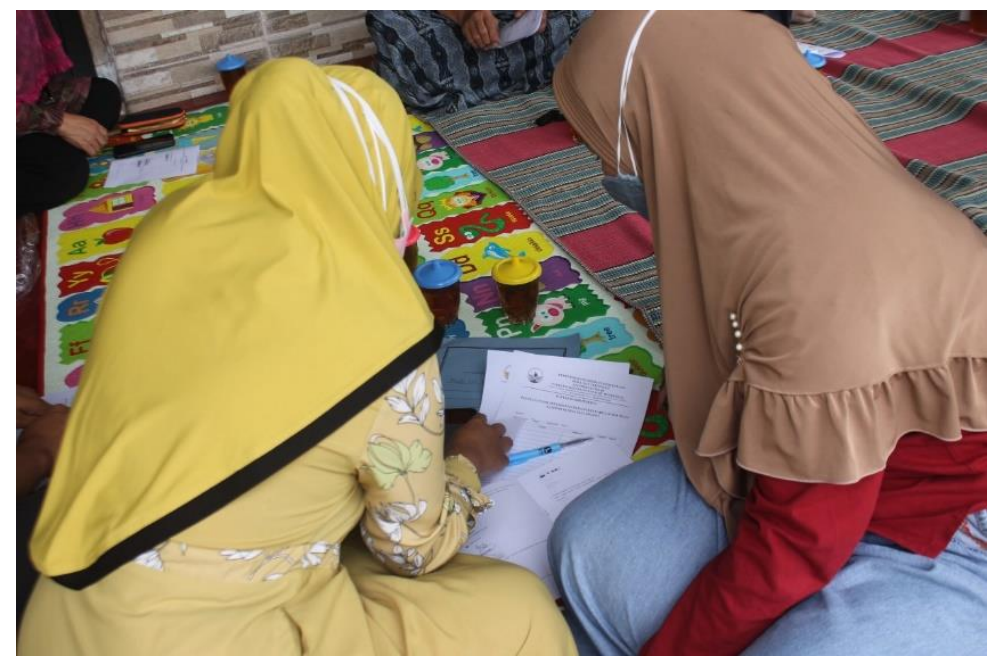

Gambar 4. Pelaksaan Pelatihan Hari Ketiga 
Adanya Kemampuan Ibu-ibu Anggota PKK Desa Salamkanci dalam Memanfaatkan Teknologi untuk Berwirausaha Guna Memenuhi Kebutuhan Ekonomi Pada Masa Pandemi

Hasil pengabdian menunjukkan bahwa adanya kemampuan ibu-ibu anggota PKK dalam memanfaatkan teknologi untuk berwirausaha guna memenuhi kebutuhan ekonomi pada masa pandemi. Hal ini dapat dilihat dari praktek penggunaan e-commerce dan tugas yang telah dikerjakan oleh ibu-ibu anggota PKK selama pengabdian dilaksanakan.

\section{KESIMPULAN}

Pelatihan dilaksanakan dengan metode ceramah, tanya jawab, simulasi dan tugas akhir kegiatan pengabdian kepada masyarakat yang dilaksanakan selama 8 bulan mulai dari pembuatan proposal sampai dengan penyusunan laporan akhir. Berdasarkan hasil dan pembahasan pada pelaksanaan pengabdian yang telah dilakukan, bahwa adanya kemampuan ibu-ibu anggota PKK Desa Salamkanci, Kec. Bandongan, Kab. Magelang dalam memanfaatkan teknologi untuk berwirausaha guna memenuhi kebutuhan ekonomi pada saat pandemi.

\section{DAFTAR PUSTAKA}

Hardiyanto, L. (2018). Motivasi mahasiswa menjadi stratup digital entrepreneurship (techmopreneurship). Jurnal IImu Pendidikan (JIP) STIKIP Kusuma Negara, 10(1).

Misnawati \& Yusriadi. (2018). Efektivitas Pengelolaan Kewirausahaan Berbasis Kognitif Personal Melalui Penggunaan Infrestruktur Digital. JMM Online, 2(3), 138-145. 